\title{
Liminality and transfer to adult services: A qualitative investigation involving young people with cystic fibrosis
}

\author{
Stephanie Tierney ${ }^{\mathrm{a}, *}$, Christi Deaton ${ }^{\mathrm{a}}$, Andrew Jones ${ }^{\mathrm{b}}$, Helen Oxley ${ }^{\mathrm{b}}$, Judith Biesty ${ }^{\mathrm{b}}$, Sue Kirk ${ }^{\mathrm{a}}$ \\ a School of Nursing, Midwifery and Social Work, University of Manchester, Manchester, UK \\ ${ }^{\mathrm{b}}$ Manchester Adult Cystic Fibrosis Centre, Manchester, UK
}

\section{A R T I C L E I N F O}

\section{Article history:}

Received 27 January 2012

Received in revised form 27 April 2012

Accepted 30 April 2012

\section{Keywords:}

Adolescents

Cystic fibrosis

Liminality

Paediatrics

Qualitative research

Semi-structured interviews

Transfer

\begin{abstract}
A B S T R A C T
Background: Moving to adult care can be challenging for adolescents with a long-term condition; if not managed well it may result in non-adherence, failure to attend appointments and a decline in health post-transfer. Life expectancy for those with cystic fibrosis has improved considerably in recent decades. This patient group was selected as an exemplar for thinking about the movement of care from paediatric to adult services. Objectives: To explore young people's experience of transferring.

Design: A qualitative descriptive methodology, involving semi-structured interviews. Setting: One adult cystic fibrosis unit in the United Kingdom.

Participants: 19 patients $(12=$ male $)$ who had moved to the study site no more than 12 months prior to data collection, which took place between October 2010 and February 2011.

Methods: Interviews were conducted face-to-face, by telephone or email. Framework analysis was applied to interview transcripts.

Results: Data suggested transfer was a period of flux, during which participants progressed from a service that was relatively prescriptive to one that called for autonomy. They appeared to go through three stages during this process: fracturing, acclimatising and integrating. The concept of liminality was used as a lens to explore data. Liminality describes those on the threshold of a new social position and rituals that bring meaning to such change. Rites of passage, such as being visited by a member of the adult team and a first appointment within this new healthcare setting, were important because they allowed for initiation into the workings of the adult unit. However, the absence of certain rituals, including a ceremony marking departure from paediatrics, might hinder progression towards becoming an adult patient.

Conclusions: The concept of liminality proved useful for thinking about data. Additional work should explore whether it can be applied to different long-term conditions and if initiation rituals vary across services. Nurses could play a role in preparing adolescents by assessing their readiness to transfer on a regular basis and intervening to address individual needs. This would help with young people's shift from a paediatric to adult identity, hopefully preventing them from experiencing a prolonged liminal state posttransfer.
\end{abstract}

(c) 2012 Elsevier Ltd. All rights reserved.

\footnotetext{
* Corresponding author at: Jean McFarlane Building, University of Manchester, Oxford Road, Manchester M13 9PL, UK.

E-mail addresses: stephanie.tierney@manchester.ac.uk (S. Tierney), mcdeaton@manchester.ac.uk (C. Deaton), andrew.jones@uhsm.nhs.uk (A. Jones), helen.oxley@uhsm.nhs.uk (H. Oxley), judith.biesty@uhsm.nhs.uk (J. Biesty), sue.kirk@manchester.ac.uk (S. Kirk).
}

\section{What is already known about the topic?}

- Transfer of young people with a chronic illness to adult services is not always well conducted and can lead to negative outcomes (e.g. increased morbidity and hospitalisations). 
- Practitioners may not necessarily prepare patients and parents for this change in healthcare or help adolescents to develop requisite self-management skills.

\section{What this paper adds}

- Liminality is a useful framework for thinking about transfer in chronic conditions; interviewees described being betwixt services and taking full responsibility for managing their CF from parents.

- Rites of passage relating to transfer, such as having a recognised 'send-off' from paediatrics and milestones in terms of self-management skills, could be something that nursing professionals undertake to help facilitate this process of change in healthcare.

\section{Introduction}

Advances in medicine and technologies have extended life expectancy of young people with chronic illnesses considerably, with the majority now expected to survive past adolescence (Schwartz et al., 2011). Becoming an adult sees children facing a number of changes as they progress from school to the workplace and become independent from parents. Young people with a chronic illness also undergo the movement of their care from paediatric to adult services (Robertson, 2006). They should be supported and prepared for this event as they take responsibility for managing their condition (Kennedy et al., 2007) and experience a shift from family to individualorientated consultations (Sawyer, 2008).

Inadequate preparation for transfer contributes to poor adherence, failure to attend regular appointments, increased hospitalisation (Annunziato et al., 2007; Brumfield and Lansbury, 2004; Dugueperoux et al., 2008) and may impact negatively on morbidity and mortality (Somerville, 1997; Watson, 2000). Conversely, clear planning enables individuals to optimise their health and act independently (American Academy of Pediatrics, 2002). An organised transition provides young people with the requisite skills to engage in adult care and can mark the start of healthy behaviours that are continued in to adulthood (e.g. exercising regularly, eating a balanced diet, taking medication).

A better understanding of transfer from the perspective of young people could assist with developing appropriate interventions that expedite this change in the management of long-term conditions. For nurses, in particular, it is important to appreciate transfer from the patient's perspective because these professionals will have developed a close bond with young people and their families and can therefore be a source of help and guidance as they prepare to move. The investigation described in this paper uses cystic fibrosis (CF) as an exemplar for exploring the topic from service users' perspective. CF is a genetic condition that results in viscous secretions blocking many ductal organs; respiratory and gastrointestinal are the main systems affected, leading to chest infections and digestive difficulties. Other complications (e.g. diabetes, low bone mineral density and multi-resistant pathogens) become more common as people age (O'Sullivan and Freedman, 2009). To maintain their health, it is recommended that patients engage in intensive and time consuming treatments, including on-going physiotherapy and regular medication, which individuals can struggle to fit into their day (Badlan, 2006). This highlights the need for an experiential as well as a biomedical understanding of the disease, to reflect its intrapersonal and interpersonal consequences.

When CF was first recognised as a distinct disease in the 1930s those with the condition died in early childhood, whereas people born with it at the start of the 21st Century are expected to live into their 50s (Dodge et al., 2007). Consequently, a move to adult care has come to be expected for this population. We know from the existing literature that adolescents with CF would like to discuss their transfer with peers (Madge and Bryon, 2002). However, unique to this patient group is the risk of cross-infection; those with $\mathrm{CF}$ are not encouraged to interact face-to-face because they can pass harmful pathogens to one another, such as Pseudomonas aeruginosa, presence of which tends to result in increased treatment burden and poorer prognosis. Segregation policies are applied in hospitals as a consequence, limiting contact between patients with CF.

Existing articles about transfer and CF have tended to be quantitative or focus on service delivery (e.g. McLaughlin et al., 2008; Tuchman et al., 2010). Little indepth exploration, using a qualitative design, has been conducted. One study did involve semi-structured interviews with parents, young people and care providers (Dupuis et al., 2011). This Canadian research included seven families and eight healthcare professionals but centred on parents' perspectives. Mothers and fathers recalled feelings of uncertainty, adding that they tried to normalise their child's life but were constantly reminded of CF's presence due to medical procedures and appointments. Another investigation, conducted in Australia, involved in-depth interviews with six people that had CF (aged 19-34 years) who had transferred to an adult service between 3 months and 20 years prior to data collection (Brumfield and Lansbury, 2004). Participants described the strong relationship they had with paediatricians, which made the prospect of moving to a new team seem like an enormous undertaking. They also mentioned the value of a pre-transfer tour of the adult unit and receiving written information about this setting. Following their analysis of interview transcripts, Brumfield and Lansbury (2004: 233) stated that paediatric staff should have "a positive attitude towards the transition and adult care, and that they 'let go' of patients in a supportive way..." These authors concluded that young people's experience of transferring could be improved if health professionals were more aware of the views of patients, which was a key motivation for conducting the research described below.

\subsection{Liminality}

To better understand the experience of transferring to adult services, we interviewed young people with CF. In this paper we report how what participants said relates to the concept of liminality. Van Gennep (1960) first 
described the liminal state when depicting a person's movement from one social position to another. The term liminal, according to the Oxford English Dictionary, derives from the Latin for threshold. Van Gennep (1960) introduced it as a concept within anthropology when writing his seminal work The Rites of Passage, which considered transitions people undergo within life (e.g. puberty, marriage and parenthood). He wrote about the rites of passage surrounding an alteration in someone's social position. He thought that rituals brought a sense of order to a change in status, which is often associated with elaborate ceremonies (e.g. funerals and weddings) (Gardner, 1998). Building on Van Gennep's work, Turner (1969) talked about 'threshold people', those in a transient state, lacking classification or definitive identity, having shed one position prior to assuming a new one. The concept of liminality relates to "the ritual 'space' in which one is suspended, straddling or wavering between two worlds, neither here nor there..." (Charon and Montello, 2002: 180 ). It is associated with ambiguity and angst as people experience a shift in their social position.

For the research described below, liminality emerged as a relevant concept during analysis. It has not been used previously in work centred on young people's movement to adult services and, in that sense, provides a unique perspective on the topic. However, other health researchers have turned to it when exploring their findings. For example, Scott et al. (2005: 1870) described the liminal state of people identified as being 'at risk' of cancer following genetic testing, who are said to occupy "a netherworld between the healthy and the afflicted." Other articles exploring experiences of cancer (Little et al., 1998; Navon and Morag, 2004; Thompson, 2007), lupus (Mendelson, 2009), motherhood (Madge and O'Connor, 2005) and breast-feeding (Mahon-Daly and Andrews, 2002) have also been structured around this concept.

\section{Methods}

A qualitative descriptive methodology (Sandelowski, 2000) was used because of the study's exploratory nature. This approach places an emphasis on understanding experiences or events and "is not guided by an explicit set of philosophic assumptions in the form of one of the known qualitative methodologies" (Caelli et al., 2003: 2). A lack of evidence about the optimum format for transfer means that understanding how key stakeholders experience such a change in care is legitimate for informing service development.

\subsection{Participants}

Participants were recruited through one adult CF unit in the north west of England that does not have an adolescent centre and is not based in the same hospital as paediatric clinics. Young people were eligible to take part if they had transferred no more than 12 months prior to interview and were not in the end stages of the disease. Clinicians identified two individuals as inappropriate to be interviewed because they had current, particularly acute psychosocial difficulties. All other eligible patients were asked to take part. During data collection, young people were purposefully sampled to ensure variation in terms of gender, children's hospital attended and severity of illness.

Recruitment continued until data saturation occurred (i.e. failed to generate new concepts). Notes made by the first author suggested this transpired after 17 interviews. Two more participants were recruited. They did not provide additional insights but supported ideas emerging from data that had been collected already. Of 39 young people invited to take part, three declined and nine agreed to an email interview but did not respond when sent a message with initial questions, followed by a reminder. We did not hear back from eight others.

\subsection{Data collection}

A letter about the study was sent to eligible adolescents with $\mathrm{CF}$, asking them to return a contact form if they were interested in being interviewed. Participants selected their preferred method of data collection from semi-structured interviews carried out face-to-face or by telephone, which were digitally recorded and transcribed verbatim. They also had the option to respond via email. It was felt that this approach would be convenient and appealing to the age group targeted. Guidance on conducting email interviews was followed (Hunt and McHale, 2007; Meho, 2006). Responses provided through this route were saved as a Word document; to maintain anonymity they were not stored in the researcher's inbox. However, their identity was known by the interviewer because she approached patients at hospital, after sending out letters, to discuss the study with them. They provided their email address to her if wishing to respond electronically.

A topic guide was developed by the team prior to data collection, based on their experiences in the field and reading of relevant literature. Questions included:

- How prepared did you feel for the move to adults?

- Who did you talk to about the move?

- What were your first impressions of the adult clinic?

- What are your main memories of your transfer?

- What advice would you give to other young people about moving to adults?

The topic guide was used during face-to-face, telephone or email interviews. However, the flexible nature of qualitative research meant that questions changed according to what transpired during data collection.

\subsection{Analysis}

Preliminary interpretation of data was conducted in tandem with interviewing. Any ideas to arise during this early phase of analysis were recorded by the first author in a reflexive journal. Once all interviews had been completed, a systematic thematic analysis was carried out, using a recognised approach known as 'Framework' (Ritchie et al., 2003). This technique involves the following stages: (a) familiarisation with the data (becoming immersed in material collected), (b) development of a thematic framework (identifying key issues in transcripts), (c) 
indexing data (labelling key issues that emerge across cases), (d) devising a series of thematic charts (allowing for within and across case comparisons), (e) mapping and interpreting of data (looking for associations, providing explanations, highlighting key characteristics and ideas). Three of the authors (ST, CD and SK) carried out these stages. They familiarised themselves with data collected and met on two occasions to discuss this material. The first author then coded data using the computer package NVIVO-9 and developed an indexing scheme. She shared this with the other analysts and incorporated their feedback into charts that were produced in Excel. These charts summarised anonymised data from all participants. They were read and discussed by the three researchers listed above. A summary of the analysis was passed to the remaining authors, who contributed to the refinement of themes. During analysis, it was clear that what interviewees described resonated with the concept of liminality; although not used to direct analysis, data immersion suggested it was relevant to interpretation.

\subsection{Ethical considerations}

The study was approved by a local research ethics committee. Participants were provided with written information about the project and had time to discuss it with a researcher or family/friends before deciding whether or not to take part. At the interview, written consent was obtained from all interviewees, who were assured about issues relating to anonymity, confidentiality and ability to stop data collection at any point without repercussions.

\subsection{Ensuring rigour}

Guidelines produced by Elliott et al. (1999) underpinned the production of data and analysis. Meetings involving members of the research team were held on a regular basis to discuss ideas emerging from interviews. Transcripts were reviewed by more than one person to enhance theoretical sensitivity and to identify additional themes or lines of thinking. An audit trail was kept by the first author, who documented the indexing and charting of data. She also wrote a reflexive diary, recording thoughts arising from data collection and analysis. For example, she noted that some participants felt on the periphery within paediatric consultations and that the move to adult care was one of many areas of life changing for these adolescents.

\subsection{Reflexivity}

The first author, who collected all data, did not know interviewees prior to the study but has conducted previous projects involving people with CF. Other authors were two academics with a nursing background and clinicians working in CF. Only the first author was aware of the identity of interviewees, whose comments were anonymised when shared with the research team. Pseudonyms have been used when reporting direct quotations in this article.

\section{Results}

Interviews with 19 young people ( $12=$ male) took place between October 2010 and February 2011. Fourteen were conducted face-to-face at the adult CF unit and lasted an average of $40 \mathrm{~min}$. One male opted to be interviewed by telephone, which lasted half an hour. The remaining participants $(n=4)$ provided data via email. This involved more than one posting; follow-up questions were sent after receiving initial responses. Interviewees ranged in age from 17 to 19 years. The majority had been diagnosed with CF in infancy or early childhood $(n=17)$. Participants had transferred from six paediatric hospitals in the north west of England. Ten were interviewed within a month of transferring. The others had moved to the adult unit between 3 and 12 months previously.

As mentioned above, while developing themes, it was apparent that how young people described their experiences resonated with Van Gennep's (1960) work on liminality, leading to an examination of literature on this concept. Van Gennep (1960) divided the movement in and out of a liminal state into three phases: separation, marginal and aggregation. He suggested that initially, a symbolic detachment from an existing group or social position takes place. The intervening period represents the liminal phase, which people are helped to progress through by the use of associated rituals. Finally, an alternative status is assumed, whereby roles and responsibility are clear and accepted. Similar stages emerged from data generated in our interviews with young people. We labelled the three themes derived from analysis as 'fracturing' (e.g. breaking ties with staff from the children's hospital and with parents' dominance in CF management), 'acclimatising' (e.g. becoming familiar with the adult unit and grappling with expectations associated with being a patient there) and 'integrating' (e.g. perceiving oneself as part of the adult CF unit, accustomed to procedures used within this setting) (see Fig. 1).

\subsection{Fracturing}

Individuals are said to disconnect from a previous social environment or group as they enter a liminal state (Madge and O'Connor, 2005). Data suggested that transfer involved the severing of bonds developed over several years with a trusted paediatric team. For those who had a milder condition (e.g. had good lung functioning, never been an in-patient) or who had changed paediatric centre during childhood, these links were not depicted as so profound compared to young people diagnosed in infancy who continued attending the same children's hospital.

Some participants described how within paediatrics, their feelings about moving to adult services were superseded by procedural tasks, such as gathering relevant documents to forward to the adult team. Ben believed that once his transfer was set in motion paediatric staff “... didn't seem to show interest in how you felt about moving over. It was more like we've sent your notes over to that side so we're just waiting for them to reply." This resonates with findings from Dupuis et al. (2011); participants in their study said practitioners focused more on clinical parameters rather 


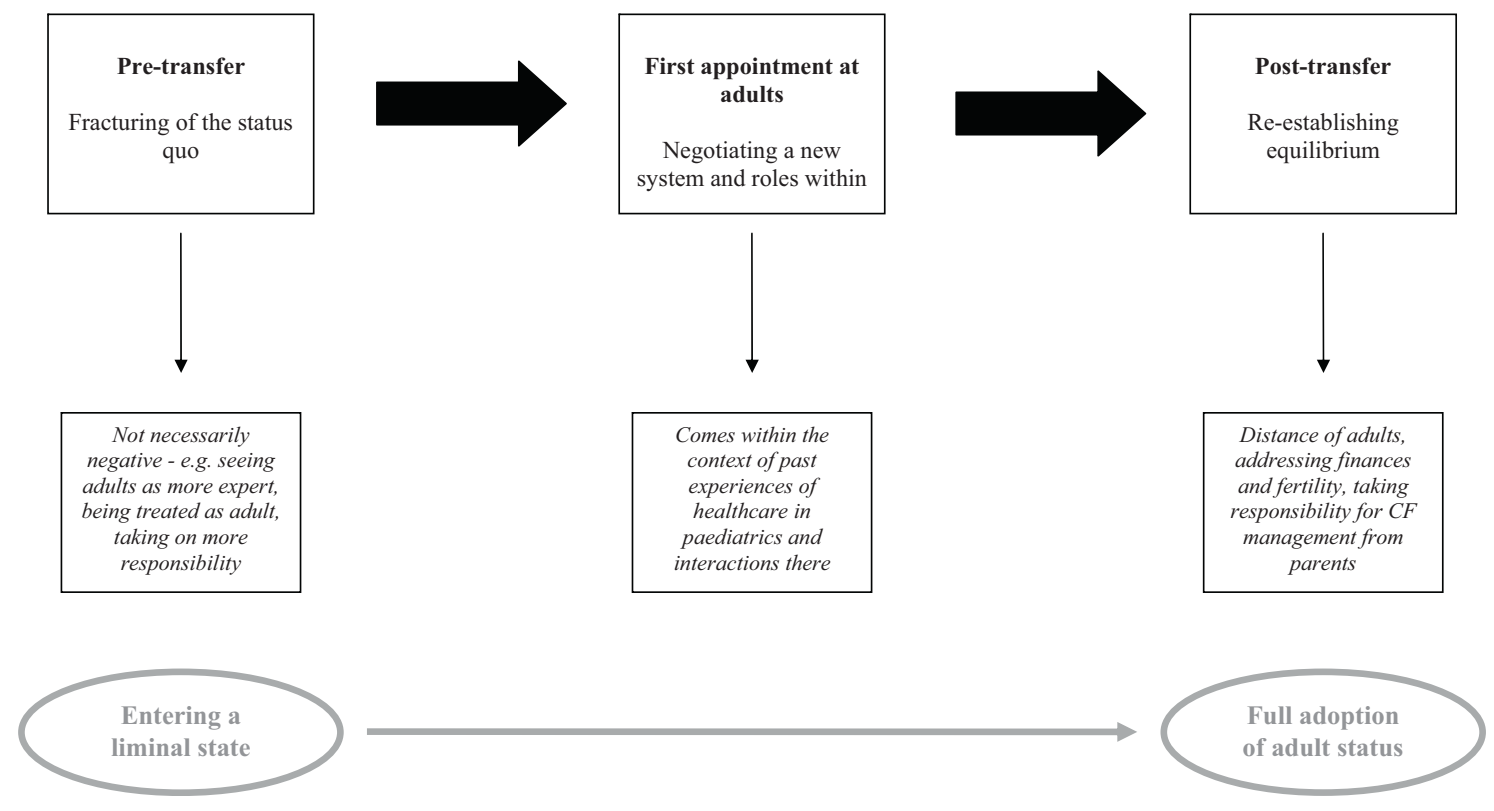

Fig. 1. Patients' passage through a liminal state.

than addressing emotional factors associated with transfer. A lack of attention to emotions might have been necessary for paediatric staff to distance themselves from families they had developed bonds with over the course of the young person's childhood and was more evident in accounts of interviewees who had only been treated at one paediatric centre.

Fracturing was not instant; participants had to wait for a date for their first appointment within the adult unit. In certain cases this was delayed when paperwork remained to be completed, leaving individuals in a state of limbo because they had already started their separation from the children's hospital. Some interviewees believed their needs were neglected while they waited to move and described being uncertain about who was responsible for their care because they straddled two services:

.. they [paediatric staff] knew I was moving up so they'd gone a bit, put me last kind of thing, so I wasn't a priority because they knew I was going to be moving up soon anyway. So they kind of, me and me mum thought not that they'd lost interest but they were making sure that the younger ones were alright because they knew I was going soon (Oliver).

Delays to transfer could explain why only one person had a 'send off' from staff at their children's hospital, even though rituals to signify the termination of paediatric care are recommended to bring closure (Reiss et al., 2005). This failure to mark clearly the ending of one set of care before proceeding to the next could prolong the liminal state and uncertainty that individuals encountered.

From a liminal perspective, as well as leaving familiar healthcare staff, fracturing also involves shedding of behaviours and attributes associated with an old identity (Turner, 1969). For young people with CF this might mean abandoning a past persona as someone uninvolved with care or a rebellious teenager, as the following comments imply:
.. I've never took it $[\mathrm{CF}]$ so serious. I've just always pushed it to one side and just tried to live a normal life but then you've got to, you can't always just put it to one side because at the end of the day it's a big part of your life... (Simon).

I suppose you rebel in the children's cause it's [physiotherapy] more a chore and I've got to do this now and I've got to do that now, whereas here [adult CF unit] it's like I should do that now because that's what I've got to do and it's my choice and I should do that because that will, that's my responsibility. It's more rewarding I suppose because you do it of your own accord instead of being told that's what you have to do (Heather).

Most interviewees recalled looking forward to being more autonomous within the adult service. Yet their narratives also suggested that parents still played a key role in providing adequate nutrition, ordering and collecting prescriptions or reminding them to carry out treatments. A fracturing of established roles therefore extends to parents who have to renegotiate their position in terms of CF and its management. This can be difficult as they tread a fine balance between reminding in a supportive manner and being perceived as 'nagging' (Karlsson et al., 2008).

\subsection{Acclimatising}

As mentioned above, Van Gennep (1960) described rites of passage that individuals undergo as they experience transitions to another life-stage, during which they encounter a liminal phase as they pass from one defined position to another. For interviewees, commencing paperwork for transfer defined the start of them shedding their paediatric identity, whereas being visited by a member of 
the new team (usually a specialist nurse) prior to moving symbolised their progression toward becoming an adult patient. The latter episode was valued by young people because they saw pictures of their new healthcare setting, which prepared them for this change in life.

The first appointment at the adult unit was another rite of passage, during which participants met staff and became familiar with how things worked there. Several interviewees depicted themselves as an outsider at this meeting, noting how the adult CF unit diverged from paediatrics. The first difference detected was the physical environment. The clinic was said to be quieter (e.g. no crying children, fewer patients waiting), less decorative (e.g. no cartoons on the wall) and not as cluttered (e.g. with toys), which acted as a visible indication that they had entered an adult-focused world. This notion was reinforced during interactions with practitioners. For example, Jane said “... as soon as the doctor started talking to me I was like, oh you're talking to me rather than me mum, which was good..." As this quotation suggests, interviewees welcomed a more direct approach and associated adult care with being listened to, making choices and playing a greater role in decision-making. However, a few who had transferred very recently felt ill-equipped emotionally to cope with this change, even if they had taken on practical tasks, such as managing their own treatments. They stated it was difficult to respond when asked for their views because this was an alien concept for them:

.. the doctor did ask me "what do you want to do?".. in childrens they wouldn't do that, they'd just say "you need IVs, you should come in." So it was quite a bit, it was a bit confusing because I didn't really know what to do myself. I was like, “I don't know, you tell me what should I do" (Clare).

Their initial consultation within an adult service was the first time some interviewees played such a central role in their care. Consequently, it was suggested they needed time to become comfortable with this style of interaction:

I'm not really one of those that will say "I don't like this, I don't like that." So it's more that that's been my problem, getting used to me having to say "I don't really agree with that"... (Heather).

During the liminal phase individuals are said to be a blank slate on which the knowledge and workings of their new environment or group can be inscribed (Turner, 1969). However, interviewees were unable to shed their old identity entirely because prior to transfer paediatric staff completed a proforma (the transfer document) outlining the person's disease history and approach to self-care. This information was sent to the adult team who used what had been written to shape the first appointment. Forwarding this transfer document could hamper participants' expressed wish to make a positive impact on their new team. A desire to create a good first impression was illustrated when interviewees recalled worrying during their initial consultation about forgetting the names and doses of medications and about being perceived negatively if accompanied by parents. Yet they did note that having their mother or father present was reassuring, reflecting their position betwixt childhood and adulthood:

.. if my mum hadn't come, I wouldn't have asked half as many questions. I don't think I'd have been as open with the doctors talking to me.. I think I'd have been a little bit more introvert and worried.. I know it sounds dead daft, me mum was there and I'm 19 but because me mum was there I was more confident in asking questions because I knew if I'd said something that had come out a funny way or the wrong way, mum would go well what she actually means is this (Jane).

Parents were the main outlet for interviewees' discussions about their apprehensiveness prior to moving, given that support from peers was limited because of segregation policies associated with cross-infection. An inability to draw on face-to-face peer support might have heightened individuals' sense of being isolated and limited their ability to become informed about care procedures within the adult unit. As noted by one interviewee who made contact with other patients via an online $\mathrm{CF}$ forum:

.. since it was mentioned in the [adult] clinic about the forums.. I went on there and it's a big eye opener that there's loads of people going through it, been through it, and they can just offer you a lot more advice from a patient side of it.. (Simon).

\subsection{Integrating}

From a liminal perspective, having cut ties with a previous environment or group and undergone a period of adjustment, individuals eventually cross the threshold into a new way of life (Madge and O'Connor, 2005). The approachable nature of their new team helped young people adapt to the adult service and to believe they could trust practitioners within it. Interviewees who had been part of this unit for several months noted how they became familiar with the team over time, adding that staff now knew them as an individual. This was important because participants had left an environment in which their preferences were seen as having been accepted and accommodated by paediatric clinicians:

.. I was with them for so long I got to know them really well and they knew I was a fussy person. But I'm sure it will all be the same with the adults (Thomas).

.. he [paediatric consultant] could tell if I was ill. I've got like a problem with my stomach and he could feel straight away if I was having, if it was worse or if it was manageable.. So he's known me for a long time. That's why I was worried about moving here.. he knew a lot of the problems that I've had.. (Lucy).

One rite of passage for some interviewees was their first stay on the adult ward. This initiation could be resisted initially because it interfered with other activities, such as starting a college course or going to work. Relocating to a new healthcare system is one of several transitions young people with a long-term condition 
experience concurrently (Kirk, 2008). Hence, transfer takes place against a backdrop of additional pressures and might not be a top priority, as this interview extract implies:

Simon: It was very busy actually because you know you've got to come in here at some point but then you've also just started at college, a new course, you don't want to miss all the beginning of your course. It's a new start both sides so you don't want to miss either one.

Interviewer: Which one do you think you gave priority to?

Simon: Urm, probably college because at this moment in time I'm not ill, I'm still managing to do my day to day things so it was college, just until I got settled in there and stuff.

The concept of liminality suggests a marginal position is temporary (Van Gennep, 1960); an endpoint is envisaged whereby individuals emerge with a changed status. For those with $\mathrm{CF}$, once their transfer takes place there is no return to being managed by paediatrics and they have to accept their position as an adult patient. From participants' accounts it appeared that all regarded the adult unit as the appropriate setting for them as they aged, in which they could address issues not usually covered by staff at children's hospitals (e.g. having a family or accessing financial benefits).

\section{Discussion}

Findings from interviewees with CF suggested that young people transferring to adult care assume a liminal state, said to arise when someone occupies a socially ambivalent life stage (Marks, 1999). This results in changes to normative relationships and behaviours, whereby order and structure are replaced by uncertainty (Navon and Morag, 2004). Such disarray, which was depicted in participants' narratives, could explain the decline in clinic attendance and health associated with a move to adult care by patients with a chronic illness (Crowley et al., 2011; Kipps et al., 2002). Establishing rites of passage can help facilitate those experiencing liminality. In our study, such initiation practices included a visit from a nurse working at the adult CF unit and a first appointment within this new setting. These rituals can be seen as facilitating young people's entry into a healthcare environment that expects them to be responsible for their disease and decisionmaking. However, an absence of formal graduation from paediatrics was noted. This lack of ceremonial 'send off' is a missed rite of passage and something that nursing staff could assist with in practice.

Certain interviewees, who had transferred recently, described their emotional attachment to the paediatric setting, but most talked about a sense of loss being overshadowed by hope of receiving care in a unit more able to meet their needs as an adult. Yet individuals might not have the skills required within an adult system. For example, some participants felt unable to voice their opinions in initial appointments. A lack of confidence in communicating with practitioners risks prolonging patients' liminal state. This is an area that paediatric nursing staff could address, by conducting transfer readiness assessments (Schwartz et al., 2011), whereby individual needs are identified as potential targets for intervention to optimise a successful outcome following transfer. Nurses could evaluate advances made in preparing young people by reassessing them on a regular basis. Transfer planning in this manner should employ a degree of structure, to ensure that key issues are covered, but allow for flexibility so that interventions can be tailored to someone's requirements. A key aim of such work would be to prevent young people from experiencing a prolonged liminal state post-transfer.

Research suggests the needs of parents surrounding transfer are often overlooked (While et al., 2004). Our participants highlighted the role mothers and fathers played at this time, providing comfort during a period of uncertainty, when direct support from peers was difficult to access because of cross-infection policies. Even though parents might concede that it is important for their child to become independent, they can struggle with relinquishing control, requiring support from practitioners to do so (Patterson and Lanier, 1999; Tuchman et al., 2008). Future research should explore in-depth parents' experiences to inform interventions that could be delivered by nurses to help mothers and fathers in facilitating their offspring's move from the liminal state as they transfer and develop a new identity as an adult patient.

Liminality is one concept that could be used to assess the success of a transitional programme. Alternatively, Schwartz et al. (2011) propose a social-ecological model, based on work by Bronfenbrenner (1979), which incorporates "socio-demographics/culture and healthcare access, patient characteristics (disease, neurocognitive and developmental status) and the inter-related components of knowledge, skills/self-efficacy, beliefs/expectancies, goals, relationships and psychosocial functioning of patients, parents and providers" (Schwartz et al., 2011: 884). This systems approach considers barriers and facilitators to a successful transfer. It incorporates all key stakeholders (young people, families and providers) and highlights variables that may be amenable to change through intervention. Nurse practitioners and researchers could consult such work when designing transitional programmes. Adopting this framework would mean not only assessing a young person's readiness for transfer but also parents and providers, allowing for the detection of specific obstacles and differences in goals or expectations between these three sets of individuals (Schwartz et al., 2011) that could be addressed via nursing-delivered interventions. This links to our data, which suggested working with all these key players is necessary to attenuate the liminal state that transferring can instigate.

\subsection{Limitations}

Face-to-face interviews were carried out at the adult CF unit. Different information might have transpired if 
conducted in participants' homes. However, data from telephone and email interviews, provided away from a clinical environment, supported information generated during interactions with young people in the hospital setting. The option of an email interview enabled us to involve those who might have been reticent to speak directly about their condition. Responses via email tended to be shorter compared to those provided face-to-face or by telephone, but they were followed up with probes (sent in second and third messages), which encouraged participants to elaborate on their initial replies. A single adult unit was used for recruitment. This site has specific ways of managing transfer. Additional research would be helpful, exploring whether different centres employ alternative rituals that might help reduce time spent by a transferring patient in a liminal state.

\section{Conclusions}

This study has revealed how young people occupy a marginal position during transfer to adult services. After shedding their previous identity as someone attending a paediatric setting, interviewees underwent rites of passage, progressing towards a modified status as an adult patient. The concept of liminality is a novel way of thinking about the move from paediatric care that could apply to other young people relocating to adult services. More research needs to be conducted to see whether this is the case, but liminality appears to be a useful concept for analysing experiences of transfer, during which adolescents and their parents undergo a change in roles and responsibilities. Factors that appeared to help interviewees emerge from a liminal state post-transfer included being part of the adult unit for several months and having an inpatient stay. Activities that might assist with this process that nurses could facilitate include the development of communication skills in paediatrics and a visit to the adult unit prior to transfer, so that young people can talk about this encounter with their children's team. Having a ceremony to symbolise 'graduation' from paediatrics could have facilitated this change in social status. More peer interaction might likewise help to overcome the sense of isolation and uncertainty that interviewees described in relation to transfer, using online resources to overcome the risks associated with crossinfection in $\mathrm{CF}$.

\section{Acknowledgments}

This study was supported by Manchester Academic Health Science Centre.

Conflict of interests: The authors declare no potential conflicts of interest with respect to the research, authorship, and/or publication of this article.

Funding: The authors disclosed receipt of the following financial support for the research: University Hospital of South Manchester NHS Foundation Trust Research Endowment Fund.

Ethical approval: This study was approved by Northwest 8 Rec Greater Manchester East Research Ethics Committee.

\section{References}

American Academy of Pediatrics, 2002. A consensus statement on health care transitions for young adults with special health care needs. Pediatrics 110, 1304-1306.

Annunziato, R.A., Emre, S., Shneider, B., Barton, C., Dugan, C.A., Shemesh, E., 2007. Adherence and medical outcomes in pediatric liver transport recipients who transition to adult services. Pediatric Transplantation 11, 608-614.

Badlan, K., 2006. Young people living with cystic fibrosis: an insight into their subjective experience. Health and Social Care in the Community $14,264-270$.

Bronfenbrenner, U., 1979. The Ecology of Human Development: Experiments by Nature and Design. Harvard University Press, Cambridge.

Brumfield, K., Lansbury, G., 2004. Experiences of adolescents with cystic fibrosis during their transition from paediatric to adult health care: a qualitative study of young Australian adults. Disability and Rehabilitation 26, 223-234.

Caelli, K., Ray, L., Mill, J., 2003. 'Clear as mud': toward greater clarity in generic qualitative research. International Journal of Qualitative Methods 2, 1-13.

Charon, R., Montello, M.M., 2002. Stories Matter: The Role of Narrative in Medical Ethics. Routledge, New York, London.

Crowley, R., Wolfe, I., Lock, K., McKee, M., 2011. Improving the transition between paediatric and adult healthcare: a systematic review. Archives of Disease in Childhood 96, 548-553.

Dodge, J.A., Lewis, P., Stanton, M., Wilsher, J., 2007. Cystic fibrosis mortality and survival in the UK: 1947-2003. European Respiratory Journal 29, 522-526.

Dugueperoux, I., Tamalet, A., Sermet-Gaudelus, I., Le Bourgeois, M., Gerardin, M., Desmazes-Dufeu, N., Hubert, D., 2008. Clinical changes of patients with cystic fibrosis during transition from pediatric to adult care. Journal of Adolescent Health 43, 459-465.

Dupuis, F., Duhamel, F., Gendron, S., 2011. Transitioning care of an adolescent with cystic fibrosis: development of systemic hypothesis between parents, adolescents, and health care professionals. Journal of Family Nursing 17, 291-311.

Elliott, R., Fischer, C.T., Rennie, D.L., 1999. Evolving guidelines for publication of qualitative research studies in psychology and related fields. British Journal of Clinical Psychology 38, 215-229.

Gardner, G., 1998. The human dimension of nosocomial wound infection: a study in liminality. Nursing Inquiry 5, 212-219.

Hunt, N., McHale, S., 2007. A practical guide to the e-mail interview. Qualitative Health Research 17, 1415-1421.

Karlsson, A., Arman, M., Wikblad, K., 2008. Teenagers with type 1 diabetes - a phenomenological study of transition towards autonomy in self-management. International Journal of Nursing Studies 45, 562-570.

Kennedy, A., Sloman, F., Douglass, J.A., Sawyer, S.M., 2007. Young people with chronic illness: the approach to transition. Internal Medicine Journal 37, 555-560.

Kipps, S., Bahu, T., Ong, K., Ackland, F., Brown, R., Fox, C., Griffin, N., Knight, A., Mann, N., Neil, H., Simpson, H., Edge, J., Dunger, D., 2002. Current methods of transfer of young people with type 1 diabetes to adult services. Diabetic Medicine 19, 649-654.

Kirk, S., 2008. Transitions in the lives of children with complex healthcare needs. Child: Care, Health and Development 34, 567-575.

Little, M., Jordens, C.F.C., Paul, K., Montgomery, K., Philipson, B., 1998. Liminality: a major category of the experience of cancer illness. Social Science and Medicine 47, 1485-1494.

Madge, S., Bryon, M., 2002. A model for transition from pediatric to adult care in cystic fibrosis. Journal of Pediatric Nursing 17, 283-288.

Madge, C., O’Connor, H., 2005. Mothers in the making? Exploring liminality in cyber/space. Transactions of the Institute of British Geographers 30, 83-97.

Mahon-Daly, P., Andrews, G.J., 2002. Liminality and breastfeeding: women negotiating space and two bodies. Health and Place 8, 61-76.

Marks, D., 1999. Disability: Controversial Debates and Psychosocial Perspectives. Routledge, London.

McLaughlin, S.E., Diener-West, M., Indurkhya, A., Rubin, H., Heckmann, R., Boyle, M.P., 2008. Improving transition from pediatric to adult cystic fibrosis care: lessons from a national survey of current practices. Pediatrics 121, e1160-e1166.

Meho, L.I., 2006. E-mail interviewing in qualitative research: a methodological discussion. Journal of the American Society for Information Science and Technology 57, 1284-1295.

Mendelson, C., 2009. Diagnosis: a liminal state for women living with lupus. Health Care for Women International 30, 390-407. 
Navon, L., Morag, A., 2004. Liminality as biographical disruption: unclassifiability following hormone therapy for advanced prostate cancer. Social Science and Medicine 58, 2337-2347.

O’Sullivan, B.P., Freedman, S.D., 2009. Cystic fibrosis. Lancet 373, 1891 1904.

Patterson, D., Lanier, C., 1999. Adolescent health transitions: focus group study of teens and young adults with special health care needs. Family and Community Health 22, 43-58.

Reiss, J.G., Gibson, R.W., Walker, L.R., 2005. Health care transition: youth, family and provider perspectives. Pediatrics 15, 112-120.

Ritchie, J., Spencer, L., O'Connor, W., 2003. Carrying out qualitative analysis. In: Ritchie, J., Lewis, J. (Eds.), Qualitative Research Practice: A Guide for Social Science Students and Researchers. Sage, London/ Thousand Oaks/New Delhi, pp. 219-262.

Robertson, L., 2006. When should young people with chronic rheumatic disease move from paediatric to adult-centred care? Best Practice and Research: Clinical Rheumatology 20, 387-397.

Sandelowski, M., 2000. Focus on research methods: whatever happened to qualitative description? Research in Nursing and Health 23, 334-340.

Sawyer, S.M., 2008. In search of quality care for adolescents and young adults with chronic conditions. Journal of Paediatrics and Child Health 44, 475-477.

Schwartz, L.A., Tuchman, L.K., Hobbie, W.L., Ginsberg, J.P., 2011. A socialecological model of readiness for transition to adult-orientated care for adolescents and young adults with chronic health conditions. Child: Care, Health and Development 37, 883-895.

Scott, S., Prior, L., Wood, F., Gray, J., 2005. Repositioning the patient: the implications of being 'at risk'. Social Science and Medicine 60, 18691879.

Somerville, J., 1997. Management of adults with congenital heart disease: an increasing problem. Annual Review of Medicine 48, 283-293.

Thompson, K., 2007. Liminality as a descriptor for the cancer experience. Illness, Crisis and Loss 15, 333-351.

Tuchman, L.K., Slap, G.B., Britto, M.T., 2008. Transition to adult care: experiences and expectations of adolescents with a chronic illness. Child: Care, Health and Development 34, 557-563.

Tuchman, L.K., Schwartz, L.A., Sawicki, G.S., Britto, M.T., 2010. Cystic fibrosis and transition to adult medical care. Pediatrics 125, 566-573.

Turner, V., 1969. The ritual process, structure and anti-structure. In: Ithaca, New York.

Van Gennep, A., 1960. The rites of passage. University of Chicago Press, Chicago.

Watson, A.R., 2000. Non-compliance and transfer from paediatric to adult transplant unit. Pediatric Nephrology 14, 469-472.

While, A., Forbes, A., Ullman, R., Lewis, S., Mathes, L., Griffiths, P., 2004. Good practices that address continuity during transition from child to adult care: synthesis of the evidence. Child: Care, Health and Development 30, 439-452. 